\begin{tabular}{|c|c|}
\hline Title & Morphology of the elytral base sclerites \\
\hline Author(s) & Sugimoto, Miwa; Ogawa, Naoki; Y oshizawa, Kazunori \\
\hline Citation & $\begin{array}{l}\text { A rthropod structure \& development, } 47(4), 423.429 \\
\text { https://doi.org/10.1016/.asd.2018.02.004 }\end{array}$ \\
\hline Issue Date & $2018-07$ \\
\hline Doc URL & http:/hdl. handle.net/2115/74843 \\
\hline Rights & $\begin{array}{l}\text { ( 2018 Elsevier, 2018. This manuscript version is made available under the CC-BY-NC-ND } 4.0 \text { license } \\
\text { http://creativecommons.org/icenses/oy-nc-nd/4.0/ }\end{array}$ \\
\hline Rights(URL) & http://creativecommons.org/icenses/by-nc-nd/4.0/ \\
\hline Type & article (author version) \\
\hline File Information & 2018A SD_Ely.pdf \\
\hline
\end{tabular}

Instructions for use 
1 ASD-D-17-00081_revised ms

2 for submission to Arthropod Structure \& Development: Special Issue of Wings and Flight

3

\section{Morphology of the elytral base sclerites}

5

6 Miwa Sugimoto, Naoki Ogawa, Kazunori Yoshizawa*

7

8 Systematic Entomology, School of Agriculture, Hokkaido University, Sapporo 060-8589, 9 Japan

10

$11 *$ correspondence: psocid@res.agr.hokudai.ac.jp

12 
13 Abstract

14 The elytral base sclerites (= sclerites located at the articular region between the forewing and 15 thorax in Coleoptera) of selected taxa were examined and homologized. Although the elytral 16 base sclerites are highly modified compared to the wing base sclerites of the other neopterans, 17 they can be homologized by using the conservative wing flapping and folding lines as 18 landmarks. A reduction of the first axillary sclerite was identified as a general trend of the 19 elytral base sclerites, although the sclerite usually has a very important function to mediate 20 flight power from the notum to the wing. This result indicates that the functional constraint 21 against the basal sclerites is relaxed because of the lack of an ability to produce flight power by elytra. In contrast, the elytral folding system formed by the basal sclerites is well retained, which probably occurs because proper wing folding is a key for the shelter function of the elytra. The elytral base sclerites apparently contain more homoplasies than the serially homologous hindwing base sclerites of Coleoptera, which suggests that the structure is less useful for higher-level systematics. However, the faster evolutionary rate of the elytral base sclerites suggests there is potential for studying the lower-level phylogeny of Coleoptera. 


\section{Introduction}

The wing base structure consists of several tightly associated sclerites located at the joint region between the wing and thorax. These sclerites play principal roles in wing flapping, rotating, and folding (Brodsky, 1994). Therefore, these sclerites are strongly constrained functionally and are known to evolve very slowly (Hörnschemeyer, 2002). In addition, the complicated shapes and articulations of the wing base sclerites make it possible to code considerable numbers of characters useful for phylogenetic estimations. Because of these properties, the wing base structure has been utilized for uncovering deep insect phylogeny (Yoshizawa \& Saigusa, 2001; Hörnschemeyer, 2002; Yoshizawa, 2007, 2011; Yoshizawa et al., 2017). Overall, the trees estimated from the wing base morphology are congruent with the results from molecular phylogenetic analyses (e.g., Ishiwata et al., 2011) and comprehensive insect phylogenomics (Misof et al., 2014).

Coleoptera are the most diversified insect order. They are characterized by highly modified forewings, called elytra, which function as a shelter against physical damage, predation, desiccation, and changes in temperature (Linz et al., 2016). The hindwing base structure of Coleoptera, which has a much less modified condition, has been studied for a wide range of taxa and utilized for higher level phylogenetic estimations (Browne \& Scholtz, 1998, 1999; Hörnschemeyer, 1998). The forewing base structure (i.e., elytral base) of Coleoptera has also been examined in some studies, but most of the observations were conducted as part of an extensive morphological study of single species and thus lacked a comparative point of view (Rivnay, 1928; Bostick, 1945; El-Kifl, 1953; Tremblay, 1958;

Doyen, 1966; Larsén, 1966). Some studies made comparative analyses, but comparisons were restricted to closely related taxa only (Stellwaag, 1914; Herbst, 1952; Ahrens, 2006; Frantsevich, 2011; Sípek et al., 2016). Therefore, most of the previous studies lacked reliable arguments about the homology and transformation of elytral base sclerites throughout the order. A couple of unique terms (e.g., basal process: Doyen, 1966; basal lobe: Larsén, 1966; elytral root: Sípek et al., 2016) have been adopted for elytral base sclerites without homologization with the wing base structure of the other Neoptera, which should also be resolved.

The wing base sclerites are also crucial for identifying the homology of the wing veins (Wootton, 1979). Homology between the elytral and wing regions (such as radial, medial, 
cubital or anal areas) is less understood, and it has been only aided based on limited fossil records of primitive Coleoptera (Kukalová-Peck \& Beutel, 2012; Kirejtshuk et al., 2014). Proper understanding of the elytral base structure may provide a clue to identify the homology of elytral regions and to identify the origin and transformation of these highly modified wings.

In this study, we observed and homologized the elytral base sclerites of selected taxa from Coleoptera. This work will form the basis for future morphological, evolutionary and functional studies of the elytra and the elytral base sclerites.

\section{Materials and Methods}

The main purpose of this study was to establish a consistent homology interpretation for the elytral base sclerites. Previously, the elytral base sclerites were examined and homologized for several coleopteran taxa (Table 1). Therefore, taxa were mainly selected from the families or their close relatives (Cerambycidae instead of Chrysomelidae) shown in Table 1. In addition, the elytral base sclerites of a species of Buprestidae (Polyphaga) was examined because of its special interest for the study of morphological transformations. The following taxa were examined: suborder Adephaga: Carabidae (Calosoma chinense) and Gyrinidae (Dineutus orientalis); suborder Polyphaga: Hytrophilidae (Hydrophilus acuminatus), Scarabaeidae (Trypoxylus dichotomus), Tenebrionidae (Andocamaia ryukyuensis), Cleridae (Enoclerus moestus), Buprestidae (Chrysodema manillarum) and Cerambycidae (Prionus insularis). Dried or alcohol-preserved specimens were used. The thorax of each specimen was removed from the other body parts and was soaked in $10 \%$ $\mathrm{KOH}$ at room temperature for one night. The soaked material was rinsed with water, followed by $80 \%$ ethanol, and then stored and observed in glycerol. To facilitate the observation of dorsal structures, the ventral structures, including the ventral layer of the wings, were removed. Observations were made using Olympus SZ60 and Olympus SZX16 binocular microscopes.

\section{Results}

(Figs. 1-8, Table 1) 
The first axillary sclerite (1Ax) of the elytral base is highly variable in the shape and the degree of development. In Carabidae, it has a posterior triangular body and an anterior arched head (Fig. 1), which was generally observed in the other neopteran 1Ax. Proximally, it articulates with the notum by two points of the body region, but the posterior articulation is looser. Apically, the head articulates with the middle part of the elytral root (as discussed by Sípek et al., 2016) along the convex axillary fold line. The head of 1Ax and the elytral root are partly fused, but this condition is uniquely observed in Carabidae. Distally, it articulates with the second axillary sclerite by two points of the body region. In Cerambycidae, the fully developed condition of 1Ax was observed, but it is less developed (Fig. 8). The head region is very weakly sclerotized. In Gyrinidae (Fig. 2) and Buprestidae (Fig. 7), the head and body regions were separated into two independent sclerites. In Scarabaeidae (Fig. 4), Tenebrionidae (Fig. 5) and Cleridae (Fig. 6), the head region is completely unsclerotized, so the articulation between $1 \mathrm{Ax}$ and elytral root is absent. In Hydrophilidae, 1 Ax is completely reduced (Fig. 3).

The second axillary sclerite $(2 \mathrm{Ax})$ is well developed throughout the examined taxa but is highly variable. In Carabidae (Fig. 1) and Gyrinidae (Fig. 2), it is triangular and articulates with the third axillary sclerite (3Ax) at its posterior tip. Although they are much narrower, these conditions are similar to conditions observed in the other neopteran wing base. In contrast, $2 \mathrm{Ax}$ has additional lobes and projections in all polyphagans: i.e., the region proximal to the $2 \mathrm{Ax}-3 \mathrm{Ax}$ articulation extends posteriorly and frequently forms a lobe-like structure (indicated by "*" in Figs 3-8). In Hydrophilidae (Fig. 3), Tenebrionidae (Fig. 5), Cleridae (Fig. 6) and Buprestidae (Fig. 7), 2Ax also has a strongly sclerotized lobe anterodistally (indicated by "+"), and its apex articulates with the elytral root along the convex axillary fold line. In Hydrophilidae (Fig. 3), Tenebrionidae (Fig. 5), Cleridae (Fig. 6), Buprestidae (Fig. 7) and Cerambycidae (Fig. 8) in which 1Ax is either reduced or absent, the anteroproximal region of $2 \mathrm{Ax}$ has a well-developed lobe (indicated by "\#") by which $2 \mathrm{Ax}$ articulates with the notum (except for Cerambycidae in which 1Ax is fully retained, although weakly sclerotized: Fig. 8). In Carabidae (Fig. 1), Gyrinidae (Fig. 2) and Cerambycidae (Fig. 8 ), $2 \mathrm{Ax}$ is separated from the elytral root by a narrow membranous furrow along the convex axillary fold line, but they are connected by a sclerotized band in Hydrophilidae (Fig. 3), Scarabaeidae (Fig. 4), Tenebrionidae (Fig. 5), Cleridae (Fig. 6) and Buprestidae (Fig. 7). The third axillary sclerite (3Ax) is highly variable in shape but always has three arms, 
as observed in the other neopteran wing base (Figs. 1-8). The anterior arm articulates with 2Ax along the concave axillary fold line. The distal arm articulates with the posterior margin of the base of the elytral base along the convex axillary fold line; the posterior arm articulates with the posterior notal wing process to forming posterior articulation of the basal hinge. The 3Ax-notal articulation seems looser in some taxa (e.g., Hydrophilidae, Fig. 3), but it is an artifact caused by the preparation of specimens for facilitating clear observation of elytral base sclerites.

The proximal median plate (PMP) of Neoptera is surrounded by $2 \mathrm{Ax}, 3 \mathrm{Ax}$ and the distal median plate, and it is delimited proximally by the concave axillary fold line and distally by the convex axillary fold line. However, in all the taxa examined here, the region is broadly membranous which shows reduction of PMP in the elytral base (Figs, 1-8). In contrast, broad sclerotization anterior to $3 \mathrm{Ax}$ can be seen in some taxa (e.g., Carabidae: Fig. 1). In addition, in Tenebrionidae (Fig. 5) and Cerambycidae (Fig. 8), this sclerotized region articulates with $2 \mathrm{Ax}$ along some distances. These results indicate that this anterior expansion of 3Ax represents a remnant of the reduced PMP. Reduction of PMP has also been identified in the Auchenorrhyncha and Coleorrhyncha of Hemiptera (Yoshizawa \& Saigusa, 2001; Yoshizawa et al., 2017), but its independent origins between Coleoptera and Hemiptera is evident.

The distal median plate (DMP) of Neoptera is delimited proximally by the convex axillary fold line. In the elytral base, the line runs from the 1Ax-elytral root or 2Ax-elytral root articulations through the posterior margin of the elytral root to the $3 \mathrm{Ax}$-elytra articulation (Figs 1-8). Therefore, the expanded posterodistal region of the elytral root was identified as DMP.

The basisubcostale (BSc) of Neoptera can consistently be identified by its articulation with the head of 1Ax. Therefore, judging from the conditions observed in Carabidae (Fig. 1) and Cerambycidae (Fig. 8), the median part of the elytral root can be unambiguously identified as BSc. In Hydrophilidae (Fig. 3), Scarabaeidae (Fig. 4), Tenebrionidae (Fig. 5) and Cleridae (Fig. 6), the head of $1 \mathrm{Ax}$ is absent, and BSc articulates with the tip of the anterodistal extension of 2Ax (indicated by "+").

Judging from the anterior borderline of BSc, as observed in Carabidae (Fig. 1), Gyrinidae (Fig. 2) and Tenebrionidae (Fig. 5), the anterior region of the elytral root can be interpreted as the humeral plate (HP). The border between BSc and HP is unclear in the other 
taxa.

The basiradiale (BR) of Neoptera can be identified by its relationship with the anterodistal part of $2 \mathrm{Ax}$. In the elytral base, the anterodistal region of $2 \mathrm{Ax}$ always articulates with the elytral root. This part of the elytral root was identified as BR. The 2Ax and BR are separated along the convex axillary fold line by a narrow membranous furrow in Carabidae (Fig. 1), Gyrinidae (Fig. 2) and Cerambycidae (Fig. 8), but they are connected by a strap of bending cuticle in other taxa (Figs. 3-7), through which the convex axillary fold line is running. Fusion between $2 \mathrm{Ax}$ and BR is widely observed in the neuropteroid orders (Zhao et al., 2014), which are close relatives of Coleoptera.

The identity of tegula ( $\mathrm{Tg}$ ) in the elytral base was less convincing. In general, the tegula is located at the most proximal part of the anterior margin of the wing base, and it is less sclerotized and frequently covered by short hairs. In Carabidae, a hairy pad is observed at the anterior corner of the notum (Fig. 1), and this condition is superficially very similar to $\mathrm{Tg}$, as observed in other winged insects. In contrast, an isolated and well sclerotized plate can be seen on the anterior wing margin of Cleridae (Fig. 6) and Cerambycidae (Fig. 8). Judging from their position, these sclerites are likely represents $\mathrm{Tg}$. In other taxa that were examined, no separable structure corresponding to Tg could be observed.

\section{Discussion}

In Carabidae, almost all fundamental elements of the neopteran wing base are retained in the elytral base (i.e., Tg, HP, 1, 2 and 3Ax, PMP, DMP, BSc and BR: Fig. 1), and they can easily be homologized with the wing base sclerites of the other Neoptera by using the wing folding lines as landmarks. In addition, each sclerite of the carabid elytral base also shows a similar condition that can be observed in the wing base of other Neoptera (e.g., 1Ax consists of a triangular body and elongated head; $2 \mathrm{Ax}$ is triangular; and $3 \mathrm{Ax}$ has three arms). In contrast, the elytral base sclerites of the other coleopteran taxa are more divergent from those observed in the other neopteran wing base structures. Comparisons between the present and previous interpretations of the elytral base sclerites are provided in Table 1. Several previous misinterpretations were identified, which mainly occurred because previous authors tried to homologize these highly modified elytral base sclerites without considering the transformation of these sclerites throughout Coleoptera and without using convincing 
landmarks (i.e., the wing folding lines as employed here and previous studies: Wootton, 1979). In addition, homology of a unique elytral structure, which has been called by a couple of local terms (basal process or elytral root) can also be identified convincingly in relation to elytral base sclerites (composite structure of HP, BSc, BR and DMP: Table 1).

Generally, the wing base sclerites are very conservative and are slowly evolving structures because of strong functional constraints acting on them (Hörnshemeyer, 2002). In contrast, the elytral base sclerites are more variable, and several modifications never seen in the wing base sclerites of the other Neoptera were identified. For example, 1Ax is divided into two separated sclerites in Gyrinidae (Adephaga: Fig. 2) and Buprestidae (Polyphaga: Fig. 7). Furthermore, these two taxa are apparently distantly related (they belong to different suborders), which shows the independent occurrences of unusual modifications. They are also completely different in their choice of habitat (aquatic Gyrinidae and arboreal Buprestidae), and thus similar modifications in 1Ax cannot be explained by convergence resulting from behavioral similarity. The modifications of the elytral base are also a contrast to the much more stable hindwing base sclerites of Coleoptera (Hörnschemeyer, 1998). The occurrence of such a contrasting evolutionary trend seen between serially homologous structures (elytral base and hindwing base sclerites) indicates there were different evolutionary pressures acting on these two structures. There are two possibilities for causing such unusual evolutionary trends in the elytral base: relaxed constraint and different selective pressures.

Among the various modifications observed in the elytral base, reduction of $1 \mathrm{Ax}$ seems to be a general trend, which includes weak sclerotization (Cerambycidae: Fig. 8), division into two sclerites (Gyrinidae and Buprestidae: Figs. 2 and 7), absence of the head (Scarabaeidae, Tenebrionidae and Cleridae: Figs. 4-6), and complete absence (Hydrophilidae: Fig. 3). Furthermore, the division of 1Ax and absence of the head were detected in distantly related taxa and thus multiple occurrences were evident. The $1 \mathrm{Ax}$ is located next to the thorax and plays a key function in mediating the power generated by the thorax to the wings (Brodsky, 1994). Tight associations between the thorax and 1Ax as well as $1 \mathrm{Ax}$ and $\mathrm{BSc} / 2 \mathrm{Ax}$ are very important for generating flapping movements. Therefore, the lack of $1 \mathrm{Ax}$ is very rarely observed among flying insects but is known also from the hindwing base of froghoppers (Hemiptera: Cicadomorpha: Cercopoidea). The reduction of $1 \mathrm{Ax}$ is also a general trend in the infraorder Cicadomorpha (Yoshizawa \& Wagatsuma, 2012). 
221 In this group, the metathorax is almost entirely occupied by the jumping muscles, and the

222 flight muscles are extremely reduced or almost completely absent. Therefore, the metathorax

223

224

225

226

227

228

229

230

231

232

233

234

235

236

237

238

239

240

241

242

243

244

245

246

247

248 lacks the ability to produce strong flight power (Ogawa \& Yoshizawa, 2017). In both cases (elytra and hindwings of Cicadomorpha), the lack of an ability to produce active flight power and the reduction of $1 \mathrm{Ax}$ seem to be connective evolutionary events. It is very likely that $1 \mathrm{Ax}$ of both groups has been relaxed from the functional constraint resulting from the lack of a function to mediate the flight power, which probably explains the general trend of the $1 \mathrm{Ax}$ reduction observed in the elytral base.

In contrast, to achieve the important protection function (Linz et al., 2016), tight associations between the left and right elytra as well as between the elytra and body must be established. Therefore, accurate control of the elytral closing movement may act as a different evolutionary constraint for the elytral base sclerite. For example, in contrast to the reduction of $1 \mathrm{Ax}, 2 \mathrm{Ax}$ and $3 \mathrm{Ax}$ of the elytral base are well developed in all the examined taxa (Figs 1-8). The basal hinge and the concave and convex axillary folding lines are the principal lines for achieving wing folding. The concave axillary folding line is formed by the $2 \mathrm{Ax}-3 \mathrm{Ax}$ articulation, and the convex axillary folding line is formed by the $2 \mathrm{Ax}-\mathrm{BR}$ articulation anteriorly and the 3Ax-elytra articulation posteriorly, which are all firmly formed in the elytral base. In the taxa with reduced 1Ax, tight articulation between $2 \mathrm{Ax}$ and the notum was observed, which forms the anterior articulation of the basal hinge along with the posterior articulation between $3 \mathrm{Ax}$ and the notum. These results suggest that the elytral base sclerite are strongly constrained for maintaining accurate closure movements. This assumption may be tested by comparing the elytral base between species with different modes of elytral opening. For example, rose chafers (Scarabaeidae: Cetoniinae) have a specialized elytral locking system and do not open elytra even during flight (Sîpek et al., 2016). In this subfamily, significant reduction of $2 A x$ and $3 A x$ are known (Herbst, 1952; Sípek et al., 2016). Therefore, it is conceivable that lack of the opening-closing function of elytra in Cetoniinae caused relaxed constraint against the accurate elytral closing mechanism and then caused reduction of $2 \mathrm{Ax}$ and $3 \mathrm{Ax}$.

Although the elytral base sclerites seem homoplasious, they may also involve some phylogenetic signal for the higher-level systematics. For example, the lobe located posteroproximal to the $2 \mathrm{Ax}-3 \mathrm{Ax}$ articulation (* in Figs. 3-8) is uniquely and consistently observed in Polyphaga. In the other neopteran wing base, $3 \mathrm{Ax}$ articulates with the posterior 
tip of $2 \mathrm{Ax}$ so that the lobe located posterior to the articular point, as observed in Polyphaga, apparently represents an apomorphic condition. The faster evolution rate of the elytral base sclerites suggests their potential for uncovering the lower-level phylogeny of Coleoptera. In this study, we selected only one species from each representative taxon so that the utility of this characteristic system for the lower-level phylogeny would not be discussed. The homology scheme of the elytral base sclerites presented here should provide a basis for future morphological, evolutionary and functional studies of this characteristic system.

\section{Acknowledgments}

We thank Masahiro Ôhara and Namiki Kikuchi for providing valuable samples for this study. This study was conducted as part of MS's master thesis and is also partially supported by the JSPS pre-doctoral fellowship and by the JSPS research grants $15 \mathrm{~J} 03697$ to NO and $15 \mathrm{H} 04409$ to $\mathrm{KY}$.

\section{References}

Ahrens, D., 2006. The phylogeny of Sericini and their position within the Scarabaeidae based on morphological characters (Coleoptera: Scarabaeidae). Systematic Entomology 31, $113-144$.

Bostick, B.O., 1945. The morphology of the carabid beetle Calosoma scrutator (Fabricius). Annals of the Entomological Society of America 38, 14-32.

Brodsky, A.K., 1994. The Evolution of Insect Flight. Oxford University Press, Oxford.

Browne, J., Scholtz, C.H., 1998. Evolution of the scarab hindwing articulation and wing base: a contribution toward the phylogeny of the Scarabaeidae (Scarabaeoidea: Coleoptera). Systematic Entomology 23, 307-326.

Browne, J., Scholtz, C.H., 1999. A phylogeny of the families of Scarabaeoidea (Coleoptera). Systematic Entomology 24, 51-84.

Doyen, J.T., 1966. The skeletal anatomy of Tenebrio molitor (Coleoptera: Tenebrionidae). Miscellaneous Publications of the Entomological Society of America 5, 103-150. 
El-Kifl, A.H., 1953. Morphology of the adult Tribolium confusum Duv. and its differentiation from Tribolium (Stene) castaneum Herbst. Bulletin de la Societe Fouad 1er d'entomologie 22, 173-249.

Frantsevich, L., 2011. Mechanisms modeling the double rotation of the elytra in beetles (Coleoptera). Journal of Bionic Engineering 8, 395-405.

Herbst, H.G., 1952. Studien über die Flügeldecken der Rutelinen und Cetoniinen (Coleoptera Scarabaeidae). Das Elytralgelenk. Zoologische Jahrbücher. Abteilung für Anatomie und Ontogenie der Tiere. 72, 1-66.

Hörnschemeyer, T., 1998. Morphologie und Evolution des Flügelgelenks der Coleoptera und Neuropterida. Bonner Zoologische Monographien 43, 1-126.

Hörnschemeyer, T., 2002. Phylogenetic significance of the wing-base of the Holometabola (Insecta). Zoologica Scripta 31, 17-29.

Ishiwata, K., Sasaki, G., Ogawa, J., Miyata, T., Su, Z.H., 2011. Phylogenetic relationships among insect orders based on three nuclear protein-coding gene sequences. Molecular Phylogenetics and Evolution 58, 169-180.

Kirejtshuk, A.G., Poschmann, M., Prokop, J., Garrouste, R., Nel, A., 2014. Evolution of the elytral venation and structural adaptations in the oldest Palaeozoic beetles (Insecta: Coleoptera: Tshekardocoleidae). Journal of Systematic Paleontology 12, 575-600.

Kukalová-Peck, J., Beutel, R.G., 2012. Is the Carbiniferous $\uparrow$ Adiphlebia lacoana really the "oldest beetle"? Critical reassessment and description of a new Permian beetle family. European Journal of Entomology 109, 633-645.

Larsén, O., 1966. On the morphology and function of the locomotor organs of the Gyrinidae and other Coleoptera. Opuscula entomologica Supplementum 30, 1-214.

Linz, D.M., Hu, A.W., Sitvarin, M.I., Tomoyasu, Y., 2016. Functional value of elytra under various stresses in the red flour beetle, Tribolium castaneum. Scientific Reports 6, 34813.

Misof, B., Liu, S., Meusemann, K., Peters, R.S., Donath, A., Mayer, C., Frandsen, P.B., Ware, J., Flouri, T., Beutel, R.G., Niehuis, O., Petersen, M., Izquierdo-Carrasco, F., Wappler, T., Rust, J., Aberer, A.J., Aspock, U., Aspock, H., Bartel, D., Blanke, A., Berger, S., Bohm, A., Buckley, T.R., Calcott, B., Chen, J., Friedrich, F., Fukui, M., Fujita, M., Greve, C., Grobe, P., Gu, S., Huang, Y., Jermiin, L.S., Kawahara, A.Y., Krogmann, L., Kubiak, M., Lanfear, R., Letsch, H., Li, Y., Li, Z., Li, J., Lu, H., Machida, R., Mashimo, 
Y., Kapli, P., McKenna, D.D., Meng, G., Nakagaki, Y., Navarrete- Heredia, J.L., Ott, M., Ou, Y., Pass, G., Podsiadlowski, L., Pohl, H., von Reumont, B. M., Schutte, K., Sekiya, K., Shimizu, S., Slipinski, A., Stamatakis, A., Song, W., Su, X., Szucsich, N.U., Tan, M., Tan, X., Tang, M., Tang, J., Timelthaler, G., Tomizuka, S., Trautwein, M., Tong, X., Uchifune, T., Walzl, M.G., Wiegmann, B.M., Wilbrandt, J., Wipfler, B., Wong, T.K., Wu, Q., Wu, G., Xie, Y., Yang, S., Yang, Q., Yeates, D.K., Yoshizawa, K., Zhang, Q., Zhang, R., Zhang, W., Zhang, Y., Zhao, J., Zhou, C., Zhou, L., Ziesmann, T., Zou, S., Li, Y., Xu, X., Zhang, Y., Yang, H., Wang, J., Wang, J., Kjer, K.M., Zhou, X., 2014. Phylogenomics resolves the timing and pattern of insect evolution. Science 346, $763-767$.

Ogawa, N., Yoshizawa, K., 2017. Morphological dissection of a behavioral trait: thoracic musclature clarifies independent development of jumping mechanisms between sister groups, planthoppers and leafhoppers (Insecta: Hemiptera: Auchenorrhyncha). Organisms Diversity \& Evolution 17, 521-530.

Richmond, E.A., 1931. The external morphology of Hydrophilus obtusatus Say (Coleoptera: Hydrophilidae). Journal of the New York Entomological Society 39, 191-251.

Rivnay, E., 1928. External morphology of the Colorado potato beetle (Leptinotarsa decemlineata Say). Journal of the New York Entomological Society 36, 125-145.

Sípek, P., Fabrizi, S., Eberle, J., Ahrens, D., 2016. A molecular phylogeny of rose chafers (Coleoptera: Scarabaeidae: Cetoniinae) reveals a complex and concerted morphological evolution related to their flight mode. Molecular Phylogenetics and Evolution 101, 163175.

Stellwaag, F., 1914. Der Flugapparat der Lamellicornier. Zeitschrift für wissenschaftliche Zoologie. 108, 359-429.

Tremblay, E. 1958. Studio morfo-biologico sulla Necrobia rufipes De G. Bollettino del Laboratorio di agricoltura "Filippo Silvestri" Portici 16, 9-140.

Wootton, R.J., 1979. Function, homology and terminology in insect wings. Systematic Entomology 4, 81-93.

Yoshizawa, K., 2007. The Zoraptera problem: evidence for Zoraptera + Embiodea from the wing base. Systematic Entomology 32, 197-204.

Yoshizawa, K., 2011. Monophyletic Polyneoptera recovered by wing base structure. Systematic Entomology 36, 377-394. 
347 Yoshizawa, K., Saigusa, T., 2001.Phylogenetic analysis of paraneopteran orders (Insecta:

Neoptera) based on forewing base structure, with comments on monophyly of Auchenorrhyncha (Hemiptera). Systematic Entomology 26, 1-13.

350 Yoshizawa, K., Wagatsuma, M., 2012. Phylogenetic relationships among superfamilies of 351 Cicadomorpha (Hemiptera: Auchenorrhyncha) inferred from the wing base structure. 352 Entomological Science 15, 408-421.

353 Yoshizawa, K., Ogawa, N., Dietrich, C.H., 2017. Wing base structure supports Coleorrhyncha $354+$ Auchenorrhyncha (Insecta: Hemiptera). Journal of Zoological Systematics and 355 Evolutionary Research 55, 199-207.

Zhao, C., Liu, X., Yang, D., 2014. Wing base structural data support the sister relationship of Megaloptera and Neuroptera (Insecta: Neuropterida). PLoS ONE 9, e114695. 
359 Figure captions

360

361 Fig. 1. Elytral base structure of Calosoma chinense (Adephaga: Carabidae)

362 Fig. 2. Elytral base structure of Dineutus orientalis (Adephaga: Gyrinidae)

363 Fig. 3. Elytral base structure of Hydrophilus acuminatus (Polyphaga: Hytrophilidae)

364 Fig. 4. Elytral base structure of Trypoxylus dichotomus (Polyphaga: Scarabaeidae)

365 Fig. 5. Elytral base structure of Andocamaia ryukyuensis (Polyphaga: Tenebrionidae)

366 Fig. 6. Elytral base structure of Enoclerus moestus (Polyphaga: Cleridae)

367 Fig. 7. Elytral base structure of Chrysodema manillarum (Polyphaga: Buprestidae)

368 Fig. 8. Elytral base structure of Prionus insularis (Polyphaga: Cerambycidae) 


\begin{tabular}{|c|c|c|c|c|c|c|c|c|c|c|}
\hline \multicolumn{2}{|c|}{ Reference I Taxa (family) \present scheme } & $\operatorname{Tg}$ & HP & BSc & BR & $1 \mathrm{Ax}$ & $2 A x$ & $3 A x$ & PMP & DMP \\
\hline Bostick (1945: fig. 17) & Carabiidae & - & Costa & $\begin{array}{l}\text { Subcosta } \\
\text { (ventral) }\end{array}$ & - & $A \times 1$ & $A \times 2$ & Ax3 (part) & Ax3? (part) & - \\
\hline Larsén (1966: fig. 9) & Gyrinidae & - & Co? & Sco & $\mathrm{Rd}$ & $1 \mathrm{Ax}$ (part) & $1 A x($ part $)+2 A x$ & $3 A x+4 A x$ & - & - \\
\hline Richmond (1931: fig. 27) & Hydrophilidae & - & \multicolumn{2}{|c|}{ ae (elytral apophysis) } & - & - & - & - & - & - \\
\hline Stellwaag (1914: figs 8-9 \& tab. XI) & Scarabaeoidea & - & \multicolumn{2}{|c|}{ lateral apophysis } & Achl (Ax1: part) & - & Achl (part) & Achll + Pf (root) & - & $\begin{array}{l}\text { median } \\
\text { apophysis }\end{array}$ \\
\hline Herbst (1952: nomenclature) & Scarabaeidae & - & L (costal lobe) & $\begin{array}{l}\text { AO1 (upper } \\
\text { apophysis 1) }\end{array}$ & $\mathrm{AO} 2$ & $A \times 1$ & $A \times 2$ & $A \times 3$ & - & $\mathrm{AO} 3$ \\
\hline Ahrens (2006: fig. 5, app. 3) & Scarabaeidae & - & hs & bsc & fm1 & - & $A \times 2$ & $A \times 3$ & - & bmp \\
\hline Frantsevich (2011: fig. 3) & Scarabaeidae & - & \multicolumn{2}{|c|}{ root } & - & $A \times 1$ & $A \times 2$ & $A \times 3$ & - & - \\
\hline Sípek et al. (2016: fig. 2) & Scarabaeidae & - & \multicolumn{2}{|c|}{ elytral root } & $\begin{array}{l}\text { Ax2-Root } \\
\text { connection }\end{array}$ & - & $A \times 2$ & $A \times 3$ & - & - \\
\hline El-Kifl (1953: fig. 25) & Tenebrionidae & - & \multicolumn{2}{|c|}{ basal process } & - & $\begin{array}{l}\text { lateral plate of } \\
\text { mesonotum? }\end{array}$ & $1 \mathrm{Ax}$ & $2 A x$ & $3 A x ?$ & - \\
\hline Doyen (1966: fig. 38) & Tenebrionidae & - & \multicolumn{2}{|c|}{ basal process } & - & - & axillary 2 & axillary 3 & - & axillary 1 \\
\hline Tremblay (1958: figs 1-2) & Cleridae & $\begin{array}{c}1 \mathrm{M} \\
\text { (mesopterale) }\end{array}$ & \multicolumn{2}{|c|}{ PBA (joint process) } & AR-2M (part) & $2 \mathrm{M}$ (part) & $2 \mathrm{M}$ (part) $(2 \mathrm{Ax})$ & $3 \mathrm{M}$ & - & - \\
\hline Rivnay (1928: fig. 15) & Chrysomelidae & - & \multicolumn{2}{|c|}{ apophysis } & - & - & - & - & - & - \\
\hline
\end{tabular}


Figure 1

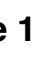

basal hinge

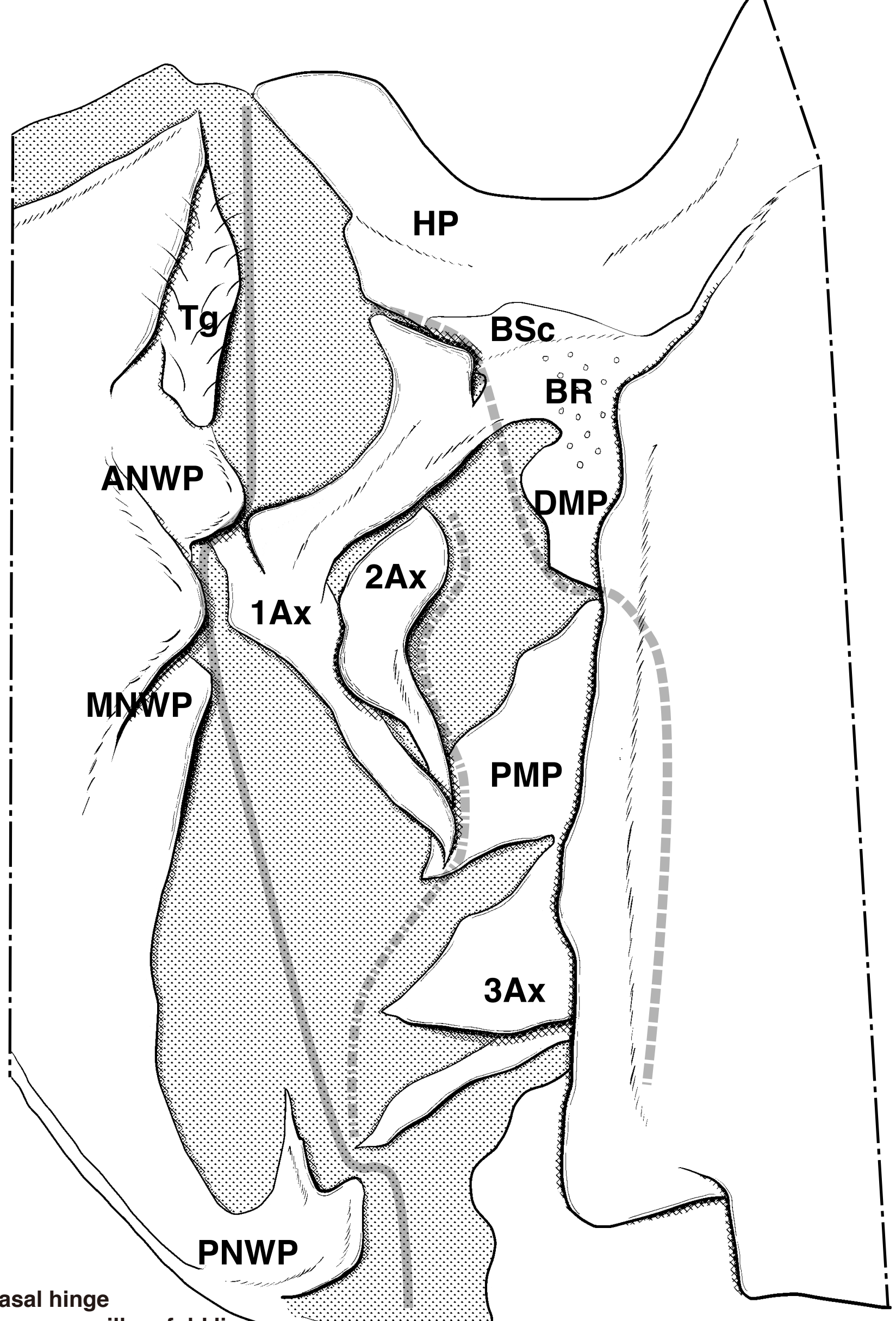
"ull convex axillary fold line 
Figure 2

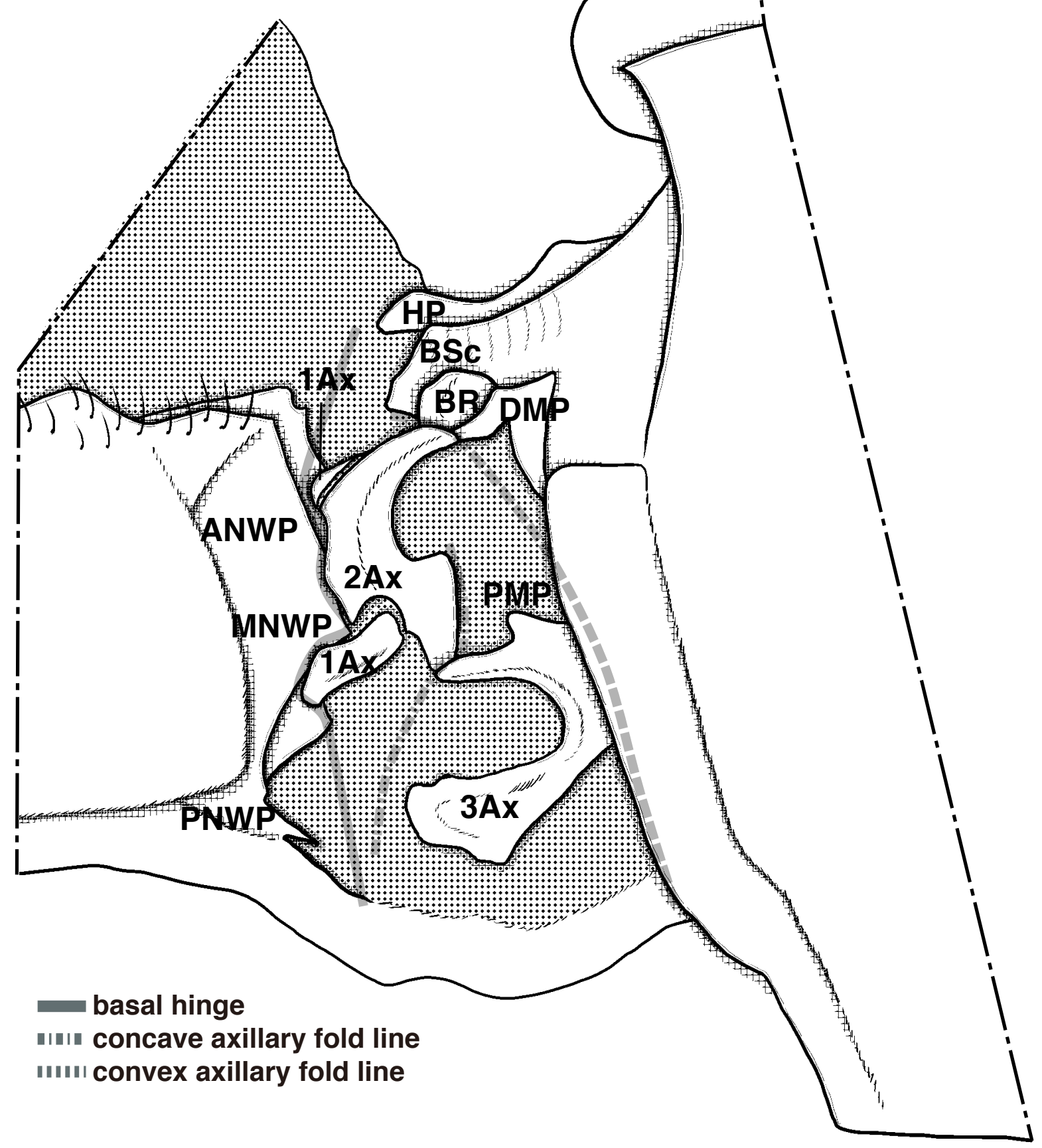


Figure 4

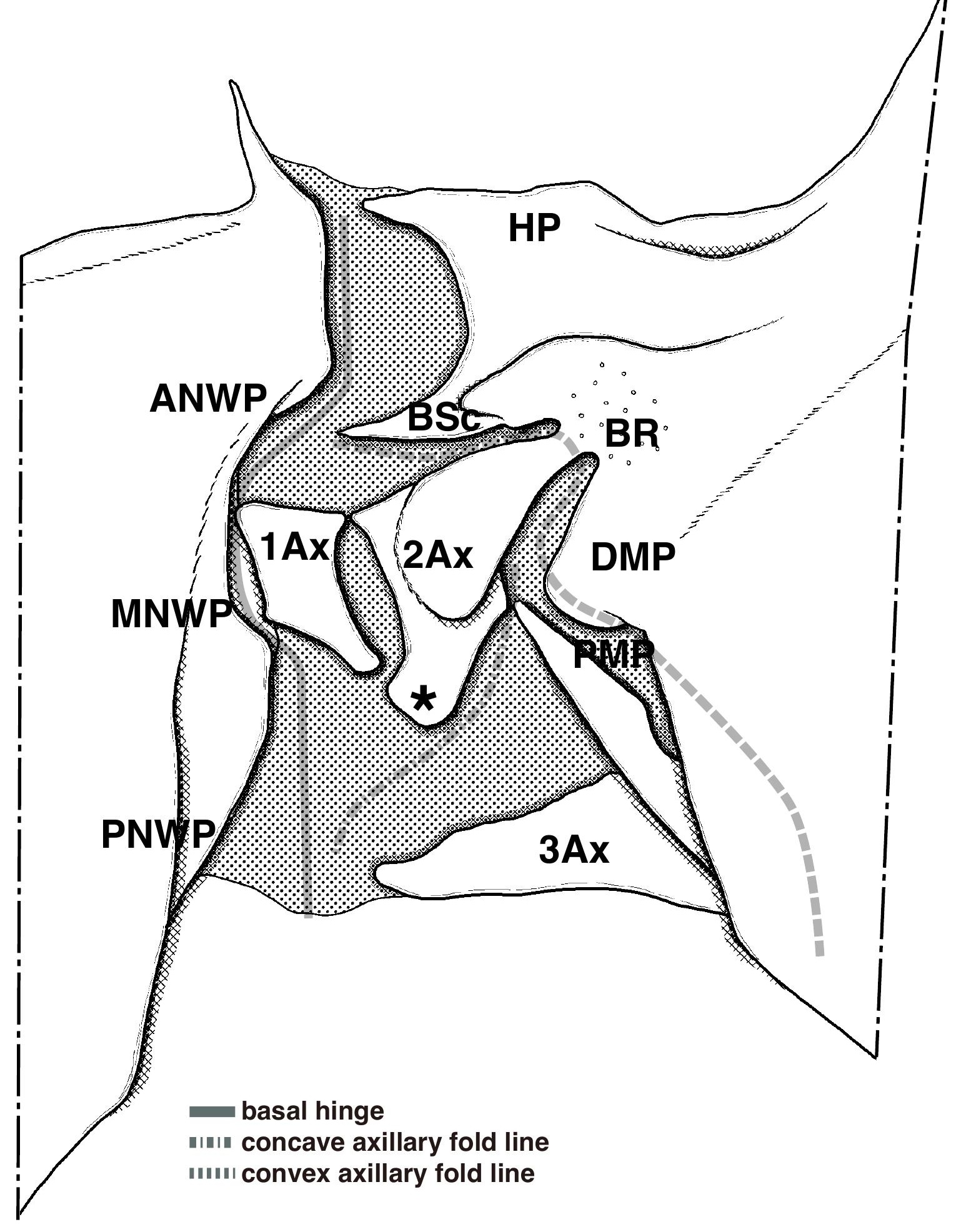


Figure 5

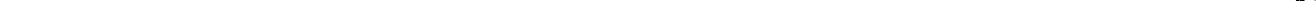


Figure 6

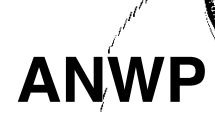

HP

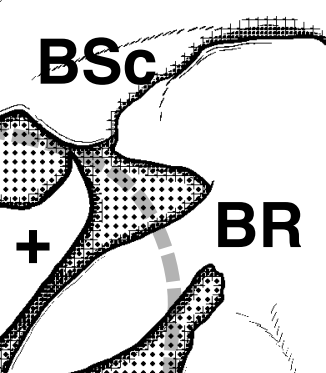

MNWP
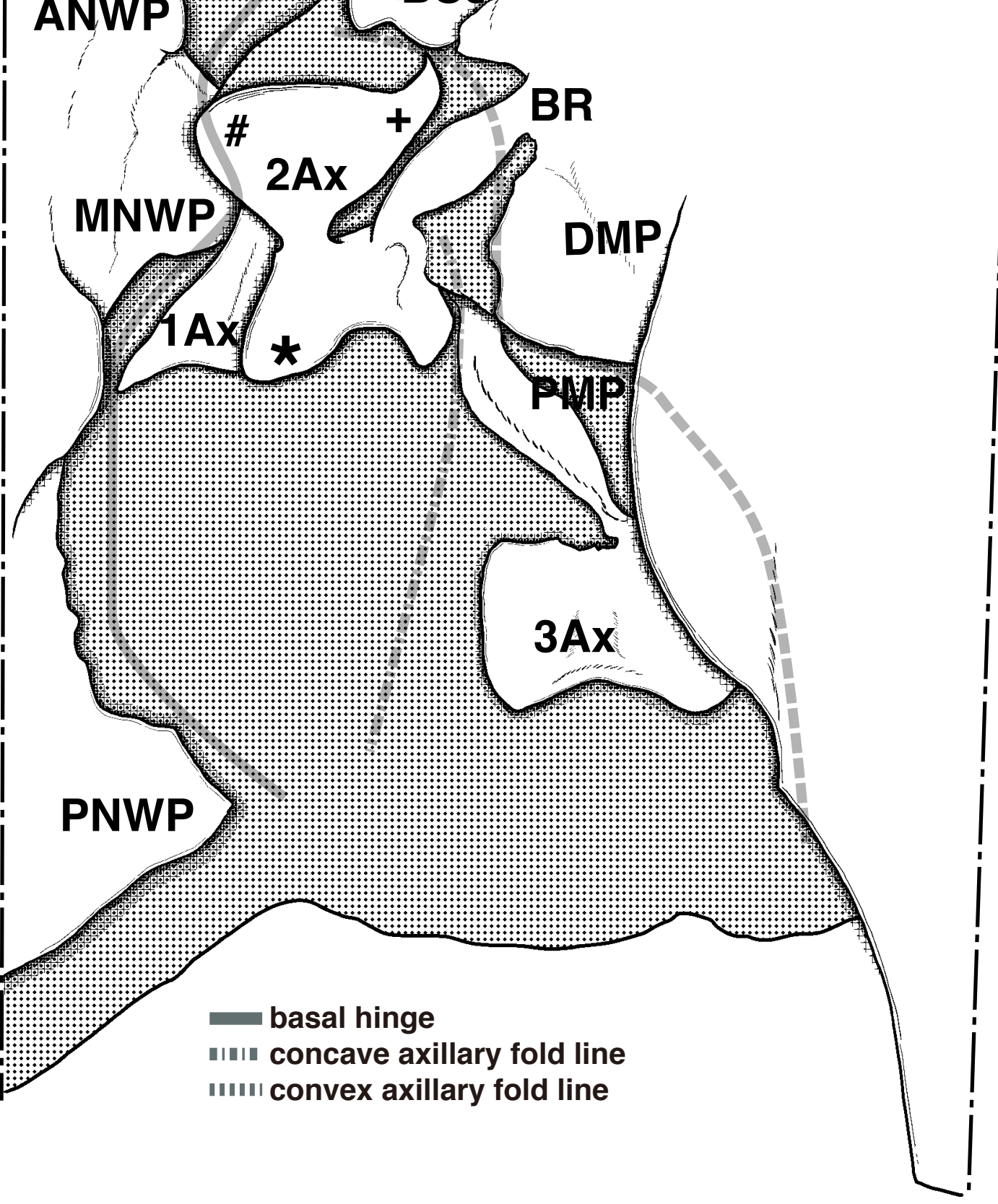

rasal hinge

concave axillary fold Iine

uru convex axillary fold line 
Figure 8

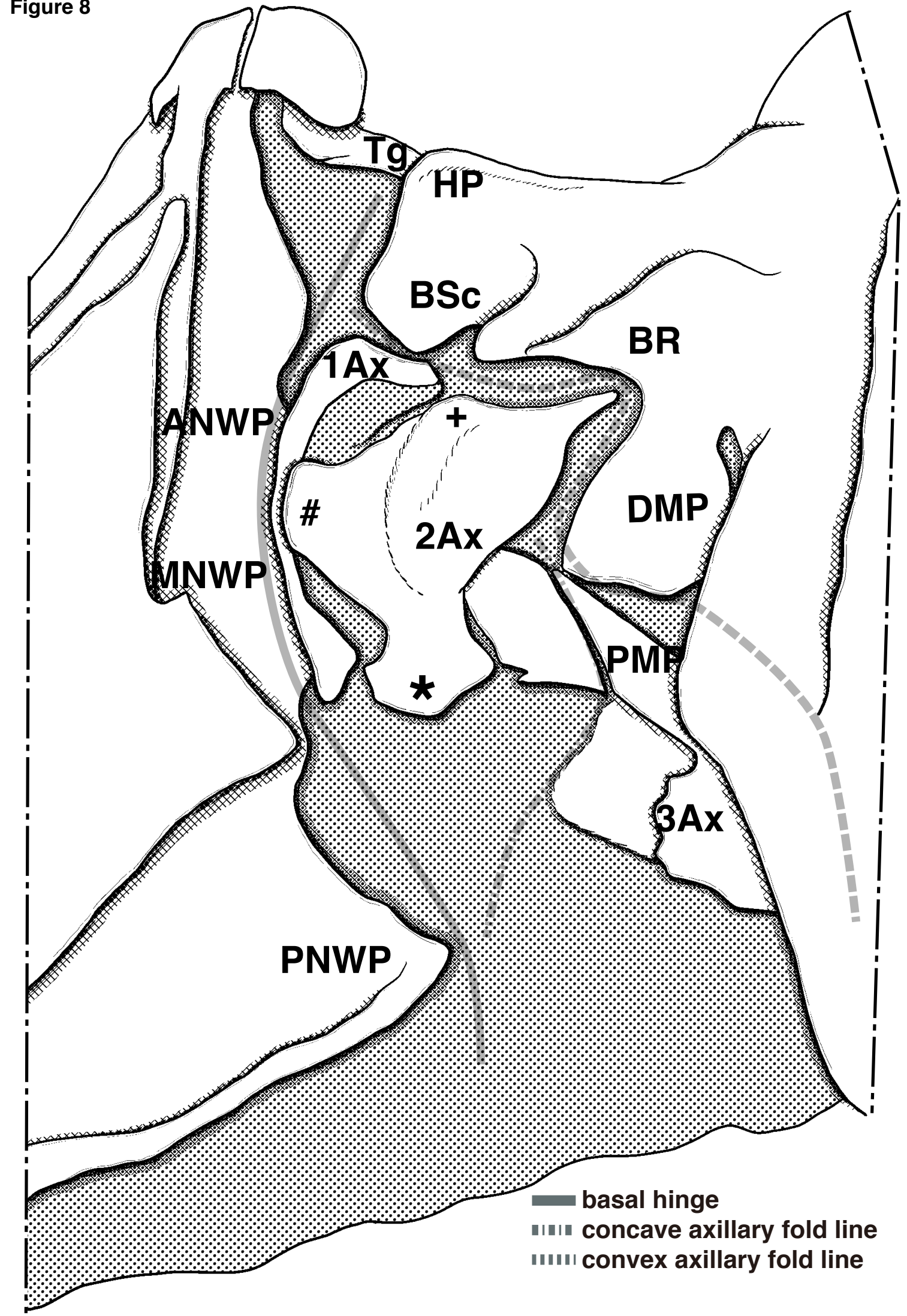

